\title{
Interactions among Florida sponges. II. Mangrove habitats
}

\author{
Sebastian Engel ${ }^{1,2}$, Joseph R. Pawlik ${ }^{1, *}$ \\ ${ }^{1}$ University of North Carolina at Wilmington, Center for Marine Science, 5600 Marvin K. Moss Lane, Wilmington, \\ North Carolina 28409, USA \\ ${ }^{2}$ Present address: Scripps Institution of Oceanography, La Jolla, California 92093, USA
}

\begin{abstract}
This study documents interference interactions between Florida sponge species. In a companion study, we conducted transect surveys to examine interspecific interactions between reef sponges in Key Largo, Florida, USA. Herein, we conducted similar transect surveys to assess interspecific interactions between mangrove sponges growing on the prop roots of the red mangrove Rhizophora mangle in Florida Bay. We surveyed 10 transect sites at 2 locations with mean densities of $2.6 \pm 0.8$ and $3.4 \pm 1.2$ sponges on each meter of prop root. Overall, $73.5 \%$ of all available root space was overgrown by a total of 1195 sponges comprising 10 species. Chondrilla nucula, Lissodendoryx isodictyalis, and Tedania ignis were the most abundant sponges and overgrew more available root space than any other species. We used a nearest-neighbor technique to determine the degree and frequency of interactions between all sponges. Overall, 31.1\% of sponges occurred alone, $3.3 \%$ in proximity to, and $65.6 \%$ in contact with other sponge species. Among all sponges in contact interactions, $39.0 \%$ were epibionts, $24.3 \%$ were basibionts, and $36.7 \%$ occurred in 'equal' interactions in which it was not possible to determine the epi- from the basibiotic species. Differences in the frequencies of each interaction category were statistically tested for all species to determine the ability of 1 sponge to overgrow or resist overgrowth by other species. Among all sponges surveyed in this study, Dysidea etheria and Clathrina canariensis were never overgrown, while Geodia gibberosa and Halichondria sp. were frequently overgrown by other species. The overgrowth ability of a sponge species appeared to be dependent on growth rate or the production of allelochemicals.
\end{abstract}

KEY WORDS: Allelopathy · Interference interactions · Mangroves · Nearest-neighbor · Overgrowth • Sponges

Resale or republication not permitted without written consent of the publisher

\section{INTRODUCTION}

This is the second of 2 studies documenting interspecific interactions among Florida sponges. In the first study, we examined interference interactions between sponge species from coral reef habitats in Key Largo, Florida, USA (Engel \& Pawlik 2005, this volume). Transect surveys coupled with nearestneighbor analyses revealed that $40 \%$ of reef sponges occurred alone, $31 \%$ in proximity to, and $29 \%$ in contact with other species. Among all sponges in contact with other species, only $38 \%$ occurred in overgrowth interactions involving clearly distinguishable epi- and basibiotic species (Engel \& Pawlik 2005). While the overgrowth ability of reef sponges appeared to be dependent on morphological growth characteristics, the ability to resist overgrowth seemed to be associated with the production of allelochemicals (Engel \& Pawlik 2000). Herein, we continued our investigation of interspecific sponge interactions by exploring interference interactions between Florida mangrove sponges. 
Mangrove habitats support a typical population of sponge species that are particularly abundant on prop roots of the red mangrove Rhizophora mangle (Rützler et al. 2000). The sponge community of mangrove prop roots is often dominated by species that are more abundant and persistent than many other sessile invertebrates, including ascidians, bryozoans, hydroids, polychaetes, mollusks, and barnacles (Sutherland 1980, Bingham \& Young 1995). Tidal exposure to air stratifies mangrove prop root communities and restricts the growth of most sponges to the subtidal portion of the root (Rützler 1995). Studies have also shown that sponges are important facultative mutualists with mangroves, protecting prop roots from root boring isopods (Perry 1988, Ellison \& Farnsworth 1990) and directly facilitating root growth by providing inorganic nitrogen (Ellison et al. 1996). In contrast, mangrove prop roots provide a nutritionally and physically advantageous substratum for sponge growth (Ellison et al. 1996). The subtidal portion of mangrove roots supports several species of sponges that are often specific to mangrove habitats (Sutherland 1980, Pawlik 1998, Rützler et al. 2000, Wulff 2005).

The distribution of Caribbean sponges in mangrove and reef habitats is primarily controlled by the abundance and activity of spongivorous predators (Dunlap \& Pawlik 1996, 1998, Pawlik 1997, 1998, Wulff 2005). Because mangrove sponges are rarely exposed to the same predation pressures as reef sponges (Dunlap \& Pawlik 1996), species that can survive the abiotic constraints of mangrove habitats attain a much greater size than on exposed reefs, where they typically grow as flat encrustations or are restricted to cryptic environments (Pawlik 1997, 1998). In the relative protection of mangrove habitats, prop roots provide an advantageous space for sponge growth. Aside from abiotic factors, larval settlement and subsequent spatial interference interactions are the most likely mechanisms controlling sponge populations on individual roots. Sutherland (1980) investigated the dynamics of prop root communities and concluded that chance settlement was a determining factor for species composition of a given prop root. Settlement experiments revealed that some species such as Tedania ignis were able to overgrow other sponges (Sutherland 1980). Wulff (2005) conducted transplant experiments to demonstrate that mangrove sponges can overgrow some reef species. Using more sophisticated field experiments, we determined that some mangrove sponges contain allelochemicals that mediate both negative and positive overgrowth interactions (Engel \& Pawlik 2000).

The purpose of this study was to investigate spatial interference interactions between sponges growing on mangrove prop roots in Key Largo, Florida, USA. Tran- sect surveys were conducted to determine local sponge demographics and examine interspecific interactions. We used a nearest-neighbor analysis to assess the degree of interaction between individual sponge species and determine their ability to overgrow or resist overgrowth by neighboring sponges. Frequencies of observed overgrowth interactions were analyzed statistically, and the resulting overgrowth patterns were further examined by comparing overgrowth ability with the allelopathic activities of sponge extracts (Engel \& Pawlik 2000).

\section{MATERIALS AND METHODS}

Study areas and sponge identification. Interspecific sponge interactions were examined on prop roots of the red mangrove Rhizophora mangle in Key Largo, Florida (Fig. 1). Ten transect sites were set up at 2 mangrove locations in the Florida Bay. Four sites were established in a small, high-flow creek connecting Lake Surprise with Sexton Cove (LSC: $25^{\circ} 10.40^{\prime} \mathrm{N}$, $80^{\circ} 23.17^{\prime} \mathrm{W}$ ), and 6 sites were established along the edges of a similar creek connecting Dusenbury Creek with Tarpon Basin (DTB: $25^{\circ} 07.92^{\prime} \mathrm{N}, 80^{\circ} 25.25^{\prime} \mathrm{W}$ ).

The sponge communities at the abovementioned mangrove locations are similar to those found throughout the tropical western Atlantic and contain most of the same species (Sutherland 1980, Rützler et al. 2000,

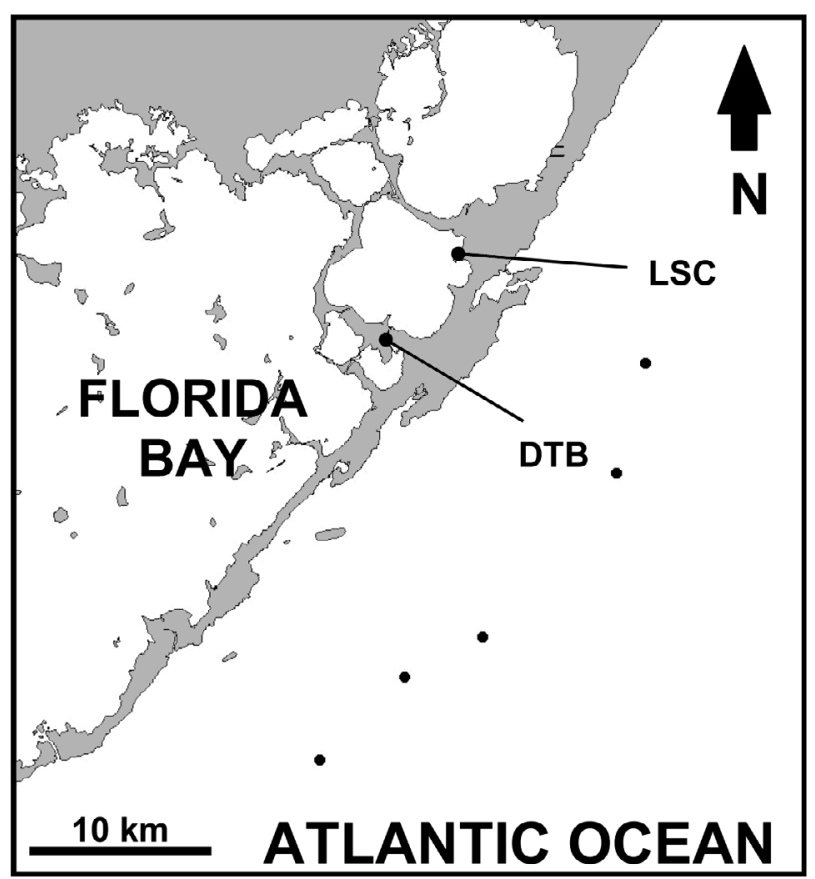

Fig. 1. Map of Key Largo indicating the location of both study locations: Lake Surprise with Sexton Cove (LSC) and Dusenbury Creek with Tarpon Basin (DTB) 
Wulff 2005). As in Engel \& Pawlik (2005), all sponge individuals were quantified by number of occurrence and each was identified by spicule and tissue preparations. Attached multiple lobes, tubes, or branches were considered part of 1 individual.

Transects and nearest-neighbor analysis. Prop roots of the red mangrove Rhizophora mangle were selected along $10 \mathrm{~m}$ line transects. All transects were set up at high tide by securing a $10 \mathrm{~m}$ transect line, marked at $1 \mathrm{~m}$ intervals, to a randomly chosen prop root and stretching it along the contour of the creek's edge. Prop roots that fell on the $1 \mathrm{~m}$ interval marks of the transect line were marked with flagging tape at the high tide watermark. The total root length available for sponge growth was determined by measuring the distance from the high tide mark to the root tip (for 'hanging' roots) or to the benthos (for 'grounded' roots). Prop roots that split into 2 or more roots were marked with cable ties and the length of each subroot was measured separately. Three transects were conducted at each site, resulting in a total sample size of 373 prop roots with a mean of $40.0 \pm 13.9 \mathrm{~m}$ of root at each transect site.

All sponge individuals occurring on marked roots were identified to species level and the length they covered on each root was recorded. In addition, interference interactions were recorded for all sponge individuals occurring on each marked root. As in Engel \& Pawlik (2005), observations of interacting sponge pairs were limited to those with a maximum distance of $5 \mathrm{~cm}$ between them. Herein, we defined the following 3 categories of interactions:

Alone: includes encounters in which a sponge is found without a neighboring sponge growing within a $5 \mathrm{~cm}$ margin from the sponges proximal and distal edges (distance to nearest-neighbor $>5 \mathrm{~cm}$ ).

Proximate: includes encounters in which a neighboring sponge is found growing within the $5 \mathrm{~cm}$ proximal or distal margins with no direct contact.

Contact: includes encounters in which 2 interacting sponges are in direct contact with each other (distance to nearest-neighbor $=0 \mathrm{~cm})$.

As in Engel \& Pawlik (2005), statistical analyses were conducted on data for sponge species that occurred 5 or more times. A chi-square goodness of fit test $\left(\chi^{2} \geq\right.$ 5.991, $\mathrm{df}=2, \mathrm{p}<0.05$ ) was used to assess differences in frequencies between the above interaction categories for each sponge species. The null hypothesis $\left(H_{0}\right)$ tested assumed equal distribution of individuals occurring alone, in proximate, or contact interactions. Rejecting the $H_{0}$ led to further investigations to examine species aggregation patterns.

All contact interactions were examined further to assess interspecific overgrowth interactions. In each case the interacting sponges were classified into 1 of 3 categories defined by the following possible outcomes:
Over: includes encounters in which the sponge occurs as the epibiont, overgrowing another species.

Under: includes encounters in which the sponge occurs as the basibiont, being overgrown by another species.

Equal: includes contact interactions in which the degree of overgrowth is not sufficient to distinguish between the epi- and basibiont. Both interacting sponges are classified as equal.

Pairs of sponge species observed in 5 or more contact interactions were chosen for statistical analysis. As in Engel \& Pawlik (2005), the overgrowth ability of each sponge species was examined by calculating the average overgrowth rate from the observed frequencies of each contact category. For each contact interaction, 2 points were assigned to the epibiont and 0 points to the basibiont. For each 'equal' interaction, 1 point was given to both sponge species. A chi-square goodness of fit test $\left(\chi^{2} \geq 3.841, \mathrm{df}=1, \mathrm{p}<0.05\right)$ was conducted on the sums of these points as the observed values, and the total number of interactions (n) was used as the expected value for both species. The $H_{0}$ tested showed that there was no difference in the overgrowth ability of the 2 interacting sponge species. If the $H_{0}$ was rejected, the species with the higher overgrow rate was regarded more likely to overgrowth the other species and considered epibiotic (Engel \& Pawlik 2005).

The extent of overgrowth of each sponge species was determined by calculating a species-specific overgrowth index using the results from the species pair analysis. The overgrowth index was calculated for each sponge species by subtracting the number of basibiotic interactions from the number of epibiotic interactions, and dividing by the total number of statistically tested pair interactions. This overgrowth index ranged from 1 to -1 , indicating a sponge that is always overgrowing other species to a sponge that is always being overgrown by other species, respectively (Engel \& Pawlik 2005).

\section{RESULTS}

\section{Sponge species abundance and diversity}

Overall, 1195 sponge individuals comprising 10 species were recorded at 2 mangrove locations (Table 1). All species were found at both locations and Morisita's index (0.8) indicated 2 similar sponge communities. While the overall percentage of sponge coverage on available root space was ca. $75 \%$ at both locations, sponge abundance was higher at LSC (56.9 \pm 20.5 ind. transect $\left.^{-1}\right)$ than at DTB $\left(30.1 \pm 9.5\right.$ ind. transect $\left.^{-1}\right)$ (Fig. 2). Overall, Chondrilla nucula was the most abundant species, with nearly 200 individuals at both loca- 
Table 1. Species abundance and diversity indices for both mangrove locations. Species with less than 5 individuals were not included. $S=$ species richness, $\mathrm{n}=$ total number of sponges, $l_{\mathrm{S}}=$ Simpson's dominance, $D_{\mathrm{S}}=$ Simpson's diversity, $E_{\mathrm{S}}=$ evenness, $\mathrm{LSC}=$ Lake Surprise with Sexton Cove, DTB = Dusenbury Creek with Tarpon Basin

\begin{tabular}{|lccc|}
\hline & Overall & LSC & DTB \\
\hline$S$ & 10 & 10 & 10 \\
$\mathrm{n}$ & 1195 & 683 & 512 \\
$l_{\mathrm{S}}$ & 0.116 & 0.116 & 0.144 \\
$D_{\mathrm{S}}$ & 0.884 & 0.884 & 0.856 \\
$E_{\mathrm{S}}$ & 0.982 & 0.981 & 0.949 \\
\hline
\end{tabular}

tions and overgrowing $34.9 \%$ of all available root space (Fig. 3). Lissodendoryx isodictyalis and Tedania ignis were also abundant, with over 150 individuals at both locations and overgrowing almost $20 \%$ of all available root space (Fig. 3). The least abundant species was a small orange encrusting sponge (Species 1) with less than 38 individuals at both locations and overgrowing only $2.4 \%$ of all available root space (Fig. 3).

\section{Interactions among sponge species}

Overall, $31.1 \%$ of all sponges on mangrove prop roots occurred alone, $3.3 \%$ in proximal, and $65.6 \%$ in contact interactions (Fig. 4a). The calcareous sponge Clathrina canariensis was the only species found alone

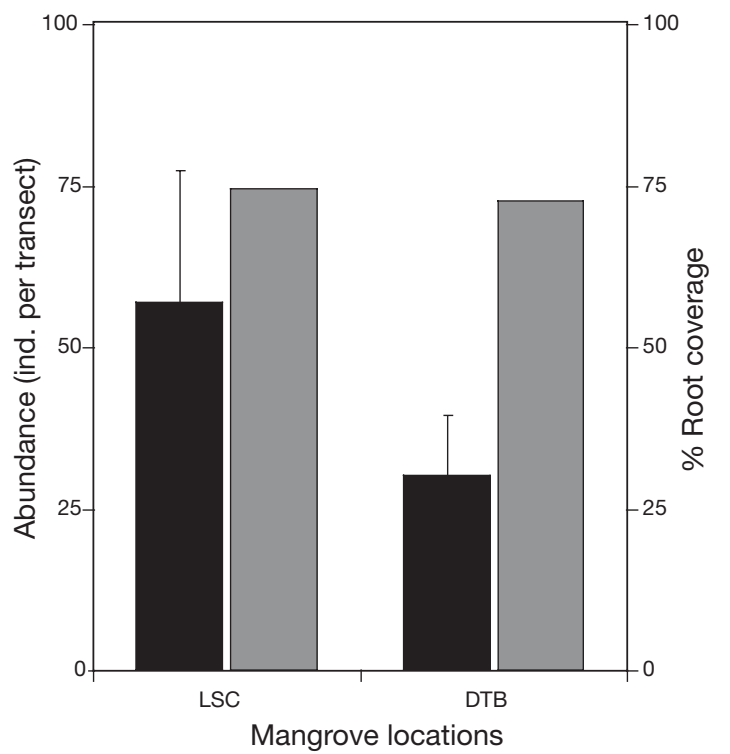

Fig. 2. Abundance of sponge individuals (mean $+\mathrm{SD}$ ) per transect (black bars), and total percentage sponge coverage of available root space (grey bars), for both mangrove locations (LSC and DTB) more frequently than in proximity to, or in contact with, other species (Fig. 4a). An unknown orange encrusting sponge (Species 1) and Chondrilla nucula occurred at nearly equal frequency alone and in contact with other species (Fig. 4a). The sponge Dysidea etheria occurred in contact in over $50 \%$, and alone in over $25 \%$ of all interactions with other species. The remaining 6 species occurred in contact more frequently than alone or in proximity to other species (Fig. 4a).

Of all sponges in contact interactions, 39.0\% occurred as epibionts, $24.3 \%$ as basibionts, and $36.7 \%$ occurred in equal interactions where it was not possible to distinguish the epi- from the basibiotic species (Fig. 4b). The sponges Clathrina canariensis, Dysidea etheria, Halichondria melanodocia, Haliclona hogarthi, and the unknown orange encrusting sponge (Species 1) occurred as epibionts in $>50 \%$ of their contact interactions (Fig. 4b). In contrast, Geodia gibberosa was the only species to occur more frequently as a basibiont and was rarely observed growing epibiotically (Fig. 4b).

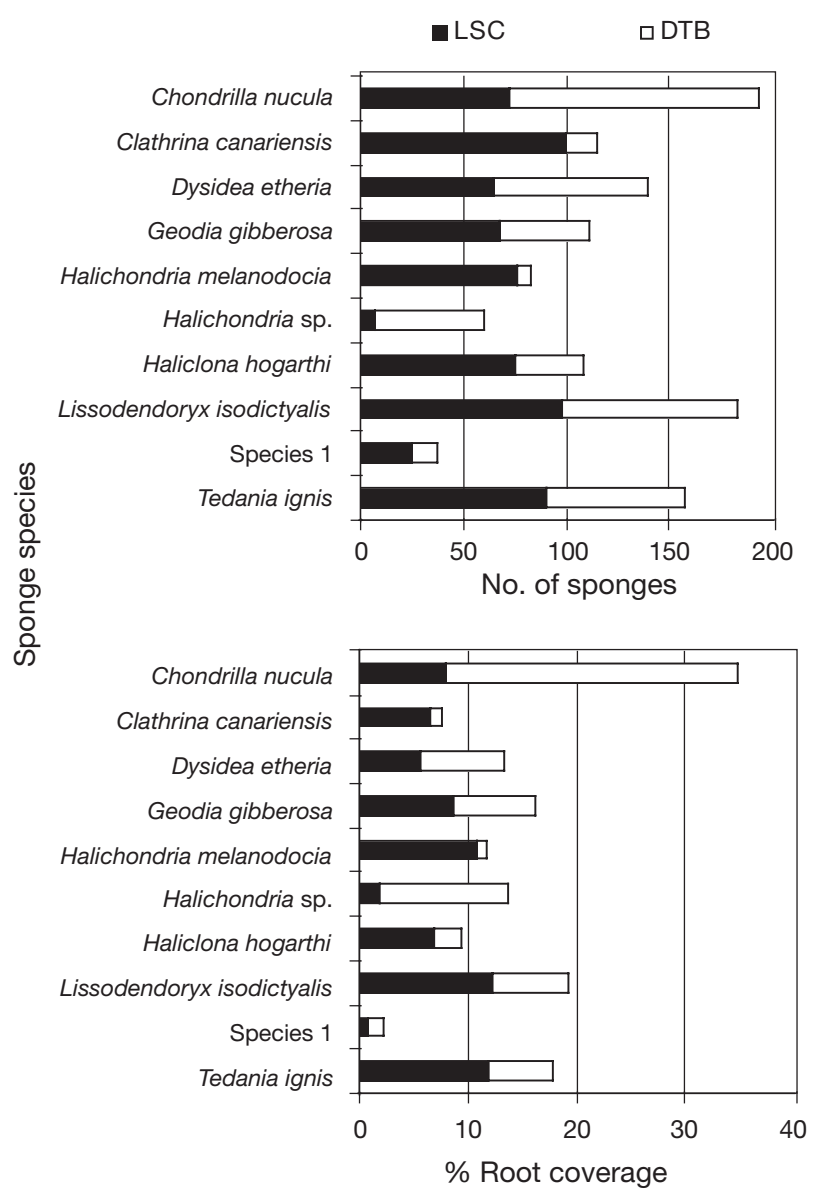

Fig. 3. Total number of sponge individuals and total percentage of sponge coverage of available root space for both mangrove locations (LSC and DTB) 


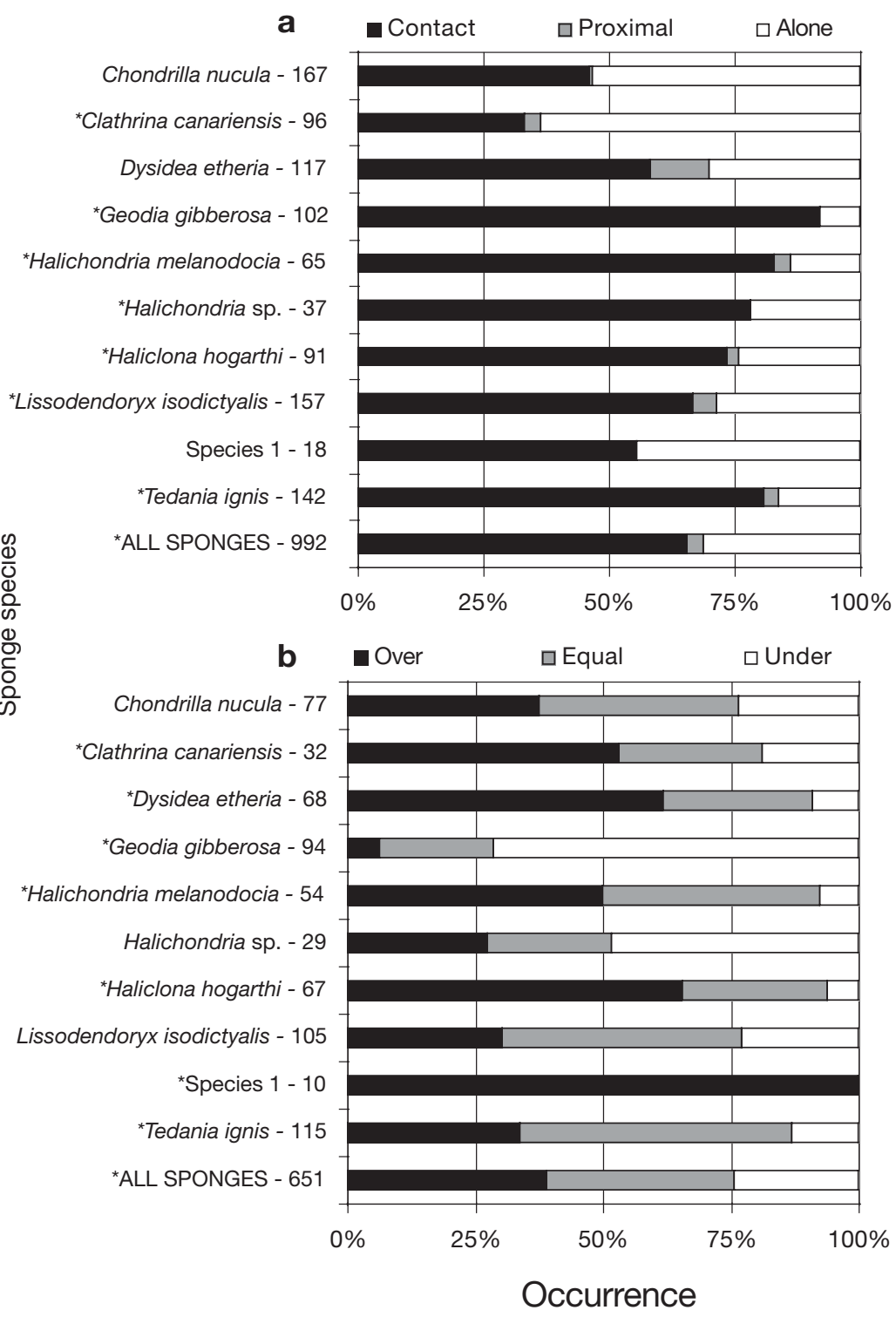

Fig. 4. Percentage occurrence of (a) contact, proximal, and no interactions (Alone) for all mangrove sponges and individual species and (b) the 3 possible outcomes (Over, Equal, Under) for contact interactions from (a). Total number of individuals is given next to the species name. *: significant results from the chi-square goodness of fit test (a) with $H_{0}$ of equal frequency and (b) conducted on assigned points with $H_{0}$ of no difference in overall overgrowth ability

The overgrowth ability of all sponges was further examined by statistically analyzing the frequencies of contact categories between each species pair. The chisquare test results for each interacting sponge pair and the resulting species-specific overgrowth indices are presented in a matrix of interspecific contact interactions (Fig. 5). The overgrowth indices were used to establish 4 levels in an overgrowth hierarchy. The top level of the hierarchy is occupied by sponges with an overgrowth index $>0.5$ and includes Dysidea etheria and Clathrina canariensis, which frequently overgrew other species and were rarely overgrown by other species (Figs. 5 \& 6). The second level is occupied by sponges with an overgrowth index between 0 and 0.5, and includes Tedania ignis, Halichondria melanodocia, and Haliclona hogarthi. The third level is occupied by sponges with an overgrowth index between 0 and -0.5 , and includes Lissodendoryx isodictyalis and Chondrilla nucula. The bottom level of the overgrowth hierarchy is occupied by sponges with an overgrowth index <-0.5, and includes Geodia gibberosa and Halichondria sp., which were frequently overgrown by other species and rarely overgrew others (Figs. 5 \& 6)

\section{DISCUSSION}

Mangrove prop roots are an advantageous substratum for sponge growth (Ellison et al. 1996) and consequently represent an important limiting resource for sponge species that can survive the abiotic constraints of mangrove habitats. Given the lack of spongivorous predators in Florida mangrove habitats (Dunlap \& Pawlik 1996, 1998, Pawlik 1998), sponge populations on mangrove prop roots are likely controlled by larval settlement dynamics and subsequent interference interactions between neighboring individuals. In this study, only 1 sponge (Clathrina canariensis) occurred more frequently alone than in proximity to, or in contact with, other species (Fig. 4a). While an unknown orange encrusting sponge (Species 1) and Chondrilla nucula occurred at nearly equal frequency alone or in contact with other species, all other species surveyed in this study occurred most frequently in contact interactions (Fig. 4a). Among all sponges in contact with other species, $63 \%$ occurred in overgrowth interactions involving clearly distinguishable epi- and basibiotic species (Fig. 4b).

Of 45 possible interspecific pair combinations among 10 sponge species, 34 pairs interacted frequently enough to be considered for statistical analysis (Fig. 5). While interactions between 13 species pairs indicated no significant overgrowth ability (NS), interactions between 21 pairs revealed species with either epi- or basibiotic tendencies. The resulting speciesspecific overgrowth indices ranged between 0.6 and 


\begin{tabular}{|c|c|c|c|c|c|c|c|c|c|}
\hline & TIGN & SP 1 & LISO & HASP & HMEL & $\mathrm{HHOG}$ & GGIB & DETH & CCAN \\
\hline CNUC & $\begin{array}{r}2 \\
\text { NS } 3 \\
4\end{array}$ & $\begin{array}{l}1 \\
2 \\
1\end{array}$ & $\begin{array}{r}3 \\
\text { NS } 6 \\
2 \\
\end{array}$ & $\begin{array}{r}17 \\
1 \quad 9 \\
4\end{array}$ & NS $\begin{array}{r}5 \\
3 \\
1\end{array}$ & $\leftarrow \begin{array}{r}2 \\
5\end{array}$ & $\begin{array}{r}18 \\
\quad 9\end{array}$ & 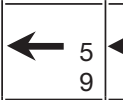 & $\begin{array}{r}6 \\
-11 \\
24\end{array}$ \\
\hline CCAN & $\begin{array}{l}2 \\
2\end{array}$ & $\begin{array}{l}1 \\
1\end{array}$ & A 7 & & & $\begin{array}{r}2 \\
\text { NS } 4\end{array}$ & $\uparrow$ & $\begin{array}{ll} & 1 \\
\text { NS } & 4 \\
& 1\end{array}$ & \\
\hline DETH & $\begin{array}{r}21 \\
4 \\
1\end{array}$ & & $\begin{array}{r}13 \\
1 \quad 15 \\
5\end{array}$ & $\begin{array}{l}6 \\
3\end{array}$ & $\begin{array}{ll} & 3 \\
N S & 3\end{array}$ & $\begin{array}{r}3 \\
\text { NS } 5 \\
3 \\
\end{array}$ & 个 $\begin{array}{r}12 \\
1\end{array}$ & & \\
\hline GGIB & $\begin{array}{r}2 \\
11\end{array}$ & $\begin{array}{r}1 \\
24\end{array}$ & $\leftarrow_{19}$ & $\begin{array}{r}5 \\
\text { NS } 3 \\
7 \\
\end{array}$ & $\begin{array}{r}\text { NS } 5 \\
2 \\
\end{array}$ & $\begin{array}{r}1 \\
\leftarrow \quad 1 \\
54 \\
\end{array}$ & & & \\
\hline $\mathrm{HHOG}$ & $\begin{array}{r}2 \\
\text { NS } 10 \\
6\end{array}$ & & $\begin{array}{l}1 \\
\text { NS } 9\end{array}$ & $\uparrow$ & $\begin{array}{r}5 \\
\leftarrow \quad 3\end{array}$ & & & & \\
\hline HMEL & $\begin{array}{r}6 \\
\text { NS } 22 \\
4 \\
\end{array}$ & & $\begin{array}{r}24 \\
1 \quad 3 \\
\end{array}$ & 个 $\begin{array}{l}7 \\
1 \\
1\end{array}$ & & & & & \\
\hline HASP & $<\begin{array}{l}1 \\
7\end{array}$ & & $\leftarrow \begin{array}{l}4 \\
8\end{array}$ & & \multirow{3}{*}{\multicolumn{5}{|c|}{$\begin{array}{l}\text { CNUC - Chondrilla nucula }(-0.1) \\
\text { CCAN - Clathrina canariensis }(0.6) \\
\text { DETH - Dysidea etheria }(0.6) \\
\text { GGIB - Geodia gibberosa }(-0.8) \\
\text { HHOG - Haliclona hogarthi }(0.3) \\
\text { HMEL - Halichondria melanodocia }(0.4) \\
\text { HASP - Halichondria sp. }(-0.9) \\
\text { LISO - Lissodendoryx isodictyalis }(-0.1) \\
\text { SP } 1 \text { - Species } 1(1.0) \\
\text { TIGN - Tedania ignis }(0.1)\end{array}$}} \\
\hline LISO & $\begin{array}{r}5 \\
\text { NS } 57 \\
15 \\
\end{array}$ & $\begin{array}{l}1 \\
2 \\
\end{array}$ & & & & & & & \\
\hline SP 1 & & & & & & & & & \\
\hline
\end{tabular}

Fig. 5. Matrix of interspecific contact interactions for all sponge species. Each cell in the matrix represents the interactions between a pair of sponge species. The top number in each cell represents the total number of occurrences in which the species in the vertical column is observed overgrowing the species in the horizontal column. Middle numbers represent the number of equal occurrences where it was not possible to identify the epi- from the basibiont. Bottom numbers represent the total number of occurrences in which the species in the vertical column is observed to be overgrown by the species in the horizontal column. Arrows represent results from the chi-square goodness of fit test, and point to the species that is more likely to be overgrown by the other. Blank cells did not have enough interactions to be considered for statistical analysis. Overgrowth index of each sponge species is given in parentheses next to the species name. $\mathrm{NS}=$ no significant overgrowth ability

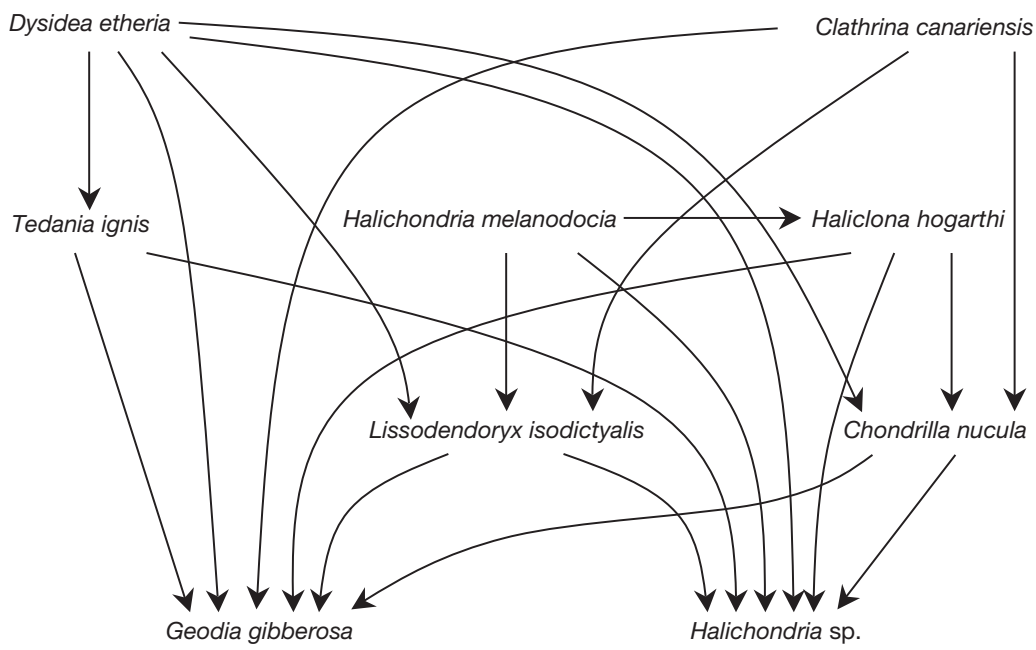

Fig. 6. Overgrowth hierarchy among 9 mangrove sponge species analyzed in the matrix of interspecific contact interactions (Fig. 5). Arrows point from the epibionts to the basibionts
-0.9 (Fig. 5), indicating highly variable overgrowth abilities among mangrove sponges (Fig. 6).

The top level of the overgrowth hierarchy is occupied by Dysidea etheria and Clathrina canariensis (Fig. 6). Interestingly, the epibiotic tendencies of these 2 species appear to be mediated by different mechanisms. The small calcareous sponge $C$. canariensis was most frequently found alone on bare root space and only $30 \%$ of all individuals occurred in contact with other species (Fig. 4a). In these contact interactions, C. canariensis occurred directly on the surface of a larger sponge with no evidence of lateral overgrowth, suggesting that its epibiotic presence was the result of a settlement event. In contrast, epibiotic D. etheria had frequently overgrown the proximal edges of 5 different basibiotic species (Fig. 6), suggesting that lateral overgrowth leads to its epibiotic condition. Organic solvent extracts from $D$. etheria inhibit sponge growth (Engel \& Pawlik 2000), and it appears that this species resists overgrowth (Fig. 6) through the production of allelopathic metabolites. In a similar study, Thacker et al. (1998) demonstrated that a related sponge of the genus Dysidea produces allelopathic metabolites that facilitate its ability to overgrow other sponge species.

The second level of the overgrowth hierarchy is occupied by Halichondria melanodocia, Tedania ignis, and Haliclona hogarthi. While $H$. melanodocia was rarely overgrown by other species, $T$. ignis and $H$. hogarthi were frequently overgrown by Dysidea etheria and H. melanodocia, respectively (Fig. 6). Further, all 3 species frequently overgrew Geodia gibberosa and Halichondria sp., which occupied the bottom level of the overgrowth hierarchy (Fig. 6). Similarly, Lissodendoryx isodictyalis and Chondrilla nucula, occupying the third level of the hierarchy, frequently overgrew both bottom level species. However, L. isodictyalis and C. nucula were also frequently overgrown by species on the first and second levels of the overgrowth hierarchy (Fig. 6). 
Interestingly, the most abundant mangrove sponges (Tedania ignis, Lissodendoryx isodictyalis, and Chondrilla nucula) (Fig. 3) ranked in the middle levels of the overgrowth hierarchy (Fig. 6). These 3 sponges can attain massive sizes ( $>0.5 \mathrm{~m}$ diameter), and covered more available root space than any other mangrove species (Fig. 3). In a previous study, we found no evidence that these sponges produce allelopathic metabolites (Engel \& Pawlik 2000), so it appears that high recruitment or fast growth are likely mechanisms for their dominance. However, because all 3 species were consistently found as basibionts to Dysidea etheria (Fig. 6), it appears that allelopathy can overcome fast growth (Engel \& Pawlik 2000).

The bottom level of the overgrowth hierarchy is occupied by Geodia gibberosa and Halichondria sp. (Figs. $5 \& 6$ ). Both of these species often grow to large sizes $(>0.5 \mathrm{~m})$ and are heavily fouled. Interestingly, overgrowth assays revealed that organic solvent extracts from G. gibberosa and Halichondria sp. promoted overgrowth by Tedania ignis, Lissodendoryx isodictyalis, and Haliclona hogarthi (Engel \& Pawlik 2000), all of which frequently overgrew both sponges (Fig. 6). Other studies have demonstrated that G. gibberosa is chemically undefended (Pawlik et al. 1995) and the preferred food for turtles and spongivorous fishes (Dunlap \& Pawlik 1996, 1998). At other sites, we found that $G$. gibberosa was often overgrown by Amphimedon erina (Engel \& Pawlik 2000), which is chemically defended against fish predators (Pawlik et al. 1995). It seems clear that $G$. gibberosa uses chemical means to gain an associational defense from predation by promoting overgrowth of chemically defended sponges in habitats where spongivorous fishes may occur (Engel \& Pawlik 2000). Wilcox et al. (2002) have also documented this 2-sponge association in grassbed and reef habitats near Plantation Key, Florida, and consider the relationship between $G$. gibberosa and $A$. erina to be a mutualistic symbiosis.

Overall, contact interactions were frequent among mangrove sponges and many resulted in the overgrowth of one species by another. Although this study did not document sponge growth rates, it was apparent from changes in relative sponge sizes over $1 \mathrm{yr}$ of investigations at these 2 mangrove locations that overgrowth ability of some species was largely dependent on the relative growth rates of interacting sponges. In contrast, we have also shown that other species use allelopathy to mediate overgrowth interactions (Engel \& Pawlik 2000). Interestingly, these species are at opposite ends of the hierarchical spectrum (Fig. 6). While Dysidea etheria uses alleopathy to resist overgrowth by other species, both Geodia gibberosa and
Halichondria sp. use it to promote overgrowth of other species that may be better defended from spongivorous fishes (Engel \& Pawlik 2000, Wilcox et al. 2002). The former situation is analogous to that described for scleractinian corals, in which some slower-growing species are able to compete for space by being more aggressive with sweeper tentacles or gastric filaments (Lang 1973).

Spatial interactions among sponges in Florida mangroves are similar to those on Florida reefs in several respects (Engel \& Pawlik 2005), most notably the clear overgrowth hierarchy that exists for each habitat. However, while that hierarchy is predicated on growth rate and allelopathy for mangrove species, it is largely dependent on the morphological growth form for reef species (Engel \& Pawlik 2005). Spatial interactions are only one kind of biotic factor that controls sponge distributions and abundances. For mangrove habitats, abiotic factors are likely to have an overarching influence on sponge ecology, with the effects of sedimentation, temperature extremes, freshwater input and hypoxia restricting a limited suite of physiologically robust sponge species to only the best flushed tidal channels and cuts (e.g. the unusual habitat described by Wulff 2005). These refuges from the worst physical extremes are also refuges from reef-dwelling, spongivorous fishes (Pawlik 1997), and with the influences of abiotic effects and predation diminished, spatial interference interactions appear to predominate among the limited suite of sponge species present in this specific type of mangrove habitat. In reef habitats, abiotic factors are less important; specifically, water quality is good and stable, promoting rich species diversity, but the presence of predatory fishes has a stronger influence on sponge ecology than do spatial interference interactions (Pawlik 1997, 1998, Engel \& Pawlik 2005). Ultimately, of course, sponge distributions and abundances are tied to a shifting spectrum of abiotic and biotic factors, including water quality, current, storms, food availability, sunlight, predation, competition, and pathogenesis, which varies from mangrove, lagoon, and grassbed habitats to patch, barrier, and deepwater reefs.

Acknowledgements. This study was funded by grants from the NOAA/National Undersea Research Program (UNCW9523, 9812) and from the National Science Foundation Biological Oceanography Program (OCE-9711255, 0095724). We thank Greg McFall and the staff of NOAA/NURC in Key Largo, Florida, for logistical support. Special thanks to Robyn M. Palmer for her daily assistance with the collection of transect data. This research benefited from the advice and counsel of Timothy P. Henkel regarding data interpretation and presentation. We also thank William G. O'Neal for his assistance in the field. Dedicated to the memory of Sophie. 


\section{LITERATURE CITED}

Bingham BL, Young CM (1995) Stochastic events and dynamics of a mangrove root epifaunal community. PSZN I: Mar Ecol 16:145-163

Dunlap M, Pawlik JR (1996) Video-monitored predation by Caribbean reef fishes on an array of mangrove and reef sponges. Mar Biol 126:117-123

Dunlap M, Pawlik JR (1998) Spongivory by parrotfish in Florida mangrove and reef habitats. PSZN I: Mar Ecol 19: 325-337

Ellison AM, Farnsworth EJ (1990) The ecology of Belizean mangrove-root fouling communities. I. Epibenthic fauna are barriers to isopod attack of red mangrove roots. J Exp Mar Biol Ecol 142:91-104

Ellison AM, Farnsworth EJ, Twilley RR (1996) Facultative mutualism between red mangroves and root-fouling sponges in Belizian Mangal. Ecology 77:2431-2444

Engel S, Pawlik JR (2000) Allelopathic activities of sponge extracts. Mar Ecol Prog Ser 207:273-281

Engel S, Pawlik JR (2005) Interactions among Florida sponges. I. Reef habitats. Mar Ecol Prog Ser 303:133-144

Lang J (1973) Interspecific aggression by scleractinian corals. 2: Why the race is not always to the swift. Bull Mar Sci 23: 260-279

Pawlik JR (1997) Fish predation on Caribbean reef sponges:

Editorial responsibility: Otto Kinne (Editor-in-Chief),

Oldendorf/Luhe, Germany an emerging perspective of chemical defenses. Proc 8th Inter Coral Reef Symp 2:1255-1258

Pawlik JR (1998) Coral reef sponges: do predatory fish affect their distribution? Limnol Oceanogr 43:1396-1399

Pawlik JR, Chanas B, Toonen RJ, Fenical W (1995) Defenses of Caribbean sponges against predatory reef fish. I. Chemical deterrency. Mar Ecol Prog Ser 127:183-194

Perry DM (1988) Effects of associated fauna on growth and productivity in the red mangrove. Ecology 69:1064-1075

Rützler K (1995) Low-tide exposure of sponges in a Caribbean mangrove community. PSZN I: Mar Ecol 16:165-179

Rützler K, Diaz MC, Van Soest RWM, Zea S, Smith KP, Alvarez B, Wulff JL (2000) Diversity of sponge fauna in mangrove ponds, Pelican Cays, Belize. Atoll Res Bull 477:231-250

Sutherland JP (1980) Dynamics of the epibenthic communitiy on roots of the mangrove Rhizophora mangle, at Bahia de Buche, Venezuela. Mar Biol 58:75-84

Thacker RW, Becerro MA, Lumbang WA, Paul VJ (1998) Allelopathic interactions between sponges on a tropical reef. Ecology 79:1740-1750

Wilcox TP, Hill T, DeMeo K (2002) Observations on a new two-sponge symbiosis from the Florida Keys. Coral Reefs 21:198-204

Wulff JL (2005) Trade-offs in resistance to competitors and predators, and their effects on the diversity of tropical marine sponges. J Anim Ecol 74:313-321

Submitted: February 14, 2005; Accepted: July 28, 2005

Proofs received from author(s): October 15, 2005 